\title{
Designing for Emergence and Innovation: Redesigning Design
}

\author{
by Greg Van Alstyne', \& Robert K. Logan ${ }^{1,2}$, \\ 'Beal Institute for Strategic Creativity, Ontario College of Art and Design, and \\ ${ }^{2}$ Department of Physics, University of Toronto
}

\begin{abstract}
This paper reveals the surprising and counterintuitive truth that design is not always at the forefront of innovation; it is a necessary but not a sufficient condition for the success of products and services. The authors argue that design must harness emergence, for it is only through this bottom-up and massively iterative, unfolding process that new and improved products and services are successfully refined, introduced and diffused into the marketplace. They articulate the similarities and differences of design and emergence, developing the hypotheses that an innovative design is an emergent design, and that a homeostatic relationship between design and emergence is a required condition for innovation. Examples of how design and emergence have interacted and led to innovation include the tool making of early man; the evolutionary chain of the six languages: speech, writing, mathematics, science, computing and the Internet; Gutenberg's printing press, and the contemporary techniques of collaborative filtering that underlie the meteoric growth of today's largest Web-based services, including Google and Amazon.com. In closing they describe the relationship between artificial and natural systems, noting that a critical trait of every successful design and living organism is its telos or purpose.
\end{abstract}

Keywords: Design, emergence, evolution, innovation, morphogenesis, organization, technology

\begin{abstract}
We believe that the introduction of a technology is not sufficient to enable a new possibility. What's necessary is our readiness to perceive that technology and to recognize its value and meaning within our lives. In order to enable new possibility, we must first discover and nurture new patterns of latent human behavior*
\end{abstract}

Beal Institute for Strategic Creativity

\section{INTRODUCTION AND OBJECTIVES}

Let us begin our discussion of design, emergence and innovation with a McLuhan 'tetrad', in which four basic questions are asked about any technology or process: what does it enhance; what does it obsolesce; what does it retrieve; and what does it reverse or flip into when pushed to the limits of its potential?

The process of design enhances innovation, Obsolesces earlier products or services, Retrieves emergence, and

Flips into a new cycle of innovation.

Design is thought to be a locus of unbridled creativity and a preeminent source of new ideas and innovation. This paper will reveal the surprising and counterintuitive truth that the design process, in and of itself, is not always at the forefront of innovation. In other words, design is a necessary but not a sufficient condition for the success of new products and services. What is missing? We intuitively sense a connection between innovative design and emergence. We will examine the nature of design, emergence, and innovation to understand their interrelationships and interdependencies. For true creativity and innovation to take place, we propose that design must harness the process of emergence; for it is only through this bottomup and massively iterative unfolding process that new and improved products and services are successfully developed, introduced, and diffused in the marketplace.

It is our belief that designers and other proponents of innovation can only be fully innovative by exploiting the natural process of emergence in their work. In examining this proposition we will address the following questions, which constitute the objectives of this paper:

1. What exactly are the relationships among design, emergence, and innovation?

2. What can designers learn from nature about emergence and evolution that will impact their thinking and their work?

3. How can innovative organizations incorporate emergence into the design process?

\section{DEFINITIONS}

Emergence is a term used in the study of complex systems, including physical, biological, social, and economic systems. Emergence refers to the process by which a higher level of organization arises through the aggregation and interaction of lower level components, 
revealing new behaviors or properties not associated with the lower level components. This characteristic pattern of emergence is elegantly and succinctly expressed in the title of Anderson's (1972) prescient paper on emergence, "More is different". Emergent structures and phenomena are observable at virtually every scale from the submicroscopic to the scale of a spiral galaxy. Classic examples of emergent forms include flocks of birds or schools of fish, giant termite "cathedrals", and certain multi-author software projects such as the open-source encyclopedia, Wikipedia.

An example of emergence that is familiar to many Internet users is the recommendation system in Amazon. com. Here collaborative filtering software is used to generate new and unpredictable patterns of related products, by methodically processing the myriad choices, explicit and implicit, made by customers as they interact with the database of displayed books, CDs, and other products. It is impossible, given just an individual click that displays, purchases, or ranks a book, to infer relationships between that book and the millions of other items in the database. Yet Amazon's system of collaborative filtering algorithms is able to organize millions of prior views and purchases and correlate these into a set of recommendations. The massive database of products and users enables emergent patterns that mimic the subtle nuances of human aesthetic and literary judgment and may even rival the accuracy of a trusted friend or colleague.

The term design refers to an intentional, human, creative process. The term is also commonly used to refer to the outcomes of that process. In this paper, however, the focus is on design as a process, understood as a "problem-solving" activity, the objective of which is the reproduction of a product, service, or other form of organization. This definition follows from Van Alstyne's (2005) one-line definition: "Design is creation for reproduction". It follows from this that design is also the propagation of organization (Kauffman et al., in press). While design is a creative process and arguably an art, it is grounded in technology and represents the application of technology to humanist purpose and benefit.

Contemporary technology is applied science; however, not all technology arose from science, as was the case with the very first tools crafted by humans or their prehuman hominid ancestors.

We will examine two kinds of design, both of which represent processes of emergence:

1. Design that creates new functions or makes a tool more functional or easier to use.

2. Design that adds value to a tool (i.e. any product) or service, above and beyond its functionality, which makes it more attractive or more playful and thereby generates what Manu (1995) has described as a ToolToy, or a tool with an element of play.
Manu states: "Products succeed on the basis of good design, but good design is no longer just a matter of function. The minimum design criteria now include emotional appeal."

Innovation refers to the process of introducing a new idea, method, device, or practice in order to secure positive change within the marketplace. The goal of innovation is to deliver increased value to the end user, for example, by launching a new product or service or by making an existing one more desirable. We make a distinction between innovation and invention. Invention is the act of creation of an advantageous and unprecedented new device or method, whereas innovation is the process of devising an invention or improvement and fitting it into the market.

The distinction between innovation and invention is significant. Consider Gutenberg's movable type printing press, which revolutionized the production of books and printed matter in the mid-fifteenth-century CE, and changed the history of the world by contributing to the emergence in Europe of modern science, the Renaissance, the Reformation, individualism, democracy, capitalism, mass education, nationalism, and a vernacular reading public (Logan, 2004a). Most scholars regard the Gutenberg press as an invention but the record of its introduction, impact, and socioeconomic diffusion marks it as a most significant innovation.

The first printing press was invented in China by Buddhist monks for the purpose of printing religious texts, in the sixth century CE - long before the work of Gutenberg. These first presses, however, did not involve movable type. The page that was to be printed was carved in reverse in a block of wood, which was inked and pressed against paper. Ink and paper, by the way, were inventions of the Chinese also. Nor was the first printing press in Europe Gutenberg's, but that of Laurens Janszoon, surnamed Coster of Haarlem in the Netherlands, who worked primarily with block prints but made occasional use of wooden type fonts. He published a religious text in 1428 . So Coster was an innovator who introduced the use of movable fonts, which he integrated with his wooden blocks carved in reverse. Hadrian Junius, who wrote a history of the Netherlands 100 years later, reported that when Coster died his shop closed, his workman dispersed, and his ideas were carried to Germany (Usher, 1954, p. 243; Putnam, 1962, pp. 351-356).

\section{Enter Gutenberg - inventor or innovator?}

Gutenberg's innovations included the exclusive use of movable type fonts and the mass production of metal type fonts that were produced by pouring molten lead into molds. Gutenberg in a certain sense inaugurated mass production, namely, the mass production of his type fonts and the books that were produced on his press. 
However, the story does not end here because it was not Gutenberg who commercialized his printing press but his business partner Fust who provided the capital for Gutenberg's work and with whom he eventually had a dispute. Gutenberg was a "geek" who wanted only to improve his invention and was not interested in the actual production of books. Fust took him to court and won a judgment in which one press was awarded to Gutenberg and one to Fust. Fust used his press to manufacture 100 copies of the Bible, which he took to Paris and sold for a handsome profit, in the process creating a riot among the manuscript writers, who rightly saw their industry coming to an end. As for Gutenberg, he went down in history as the inventor of the printing press.

Yet history should record sixth-century Chinese monks as the inventors of the press, while the work of Janszoon, Gutenberg, and Fust delivered the innovation that enhanced this technology with moveable metal type, thereby creating the revolutionary effects that arose in civic and commercial life.

The term innovation can be said to include invention implicitly, as one can trace the invention of almost every technology to some previous one. The wheel has been reinvented many times in the cart, the bicycle, the motorcar, and the airplane and probably got its start from someone rolling a heavy stone or log and noticing it was a lot easier to roll something than carry it. However, let us return to the important question we want to address, which is the relationship of design and emergence to innovation.

We wish to demonstrate that all human innovation involves the interplay of design and emergence. Both design and emergence are necessary conditions in human innovation. Neither one on its own is sufficient. Only biological innovation in nature can proceed by emergence alone.

\section{DESIGN AND EMERGENCE: SIMILARITIES AND DIFFERENCES}

Design and emergence are related but differ in important ways that we shall describe. Tables I and II outline their similarities and differences:

\section{Similarities of design and emergence}

Both design and emergence represent the propagation of organization towards a goal or purpose. In the case of emergence, which is a natural process, it is only for biotic systems that a goal or purpose exists. One cannot attribute purpose to abiotic or non-living

systems. A biotic system, or living organism, is an autonomous agent that acts on its own behalf. Its purpose or goal is the propagation of its organization through growth and replication. Through the process of evolution, which may be defined as descent with modification, an organism probes its Adjacent Possible (Kauffman, 2000), exploring every manner of innovation to its own structure. It is through the process of natural selection that those innovations that are viable are selected, and are able to propagate their organization. In some cases the new form replaces the old one from which it developed, as has happened so often in the evolution of species, but often the old form survives as well. In human design the new form sometimes replaces the old and sometimes it just changes the use of that form. Word processing and computing basically eliminated the typewriter but neither the typewriter nor the computer obsolesced the pencil or the pen. The ballpoint pen did not totally obsolesce the fountain pen but it changed its function into that of an art form.

With human-initiated design there is also a goal or purpose at work entailing the propagation of organization, namely to improve an existing product or service or create a new one. The organization that is propagated is the former product or service to be improved. In the case of a new product or service the organization that is propagated comprises the components, namely the materials and technologies out of which the new product and service is fashioned. Nothing is created ex nihilo but always begins with existing elements of a culture.

Design and emergence both represent processes of morphogenesis, as they both give birth to new forms. In the case of emergence within evolution, the new form is selected by natural selection, or survival of the most fit. In the case of design, selection is made within the marketplace of users, who collectively determine which forms are most functional and most enjoyable to use. Both emergence and design involve a bifurcation or fork in the path of development, from the original form to that of the new organism, product, or service.

\section{Differences of design and emergence}

The similarities of design and emergence are striking but we must take into account their differences. Emergence is a process of nature that does not entail human intervention or intention whereas design is characterized by human intention, cognition, and conceptualization. As such, design is characteristically a top-down process in which the designer, working as an artist does, begins with the desired effects and outcomes and looks for causes that will bring these about. In contrast, emergence is a bottom-up process in which the components of the system self-organize through their interactions with each other without a singular, overarching intention. The designer is typically in control of the design process, whereas in emergence the components of the system do not control the outcome - they merely influence it through their mutual interactions with each other. 
- Design and emergence

- Processes that entail the propagation of organization toward a goal or purpose

- Concerned with selection

- Development of differentiation from generality

- Morphogenesis (the birth of new forms)

- Bifurcation in the path of development from a lower level of organization to a higher one

Table I. Similarities of Design and Emergence

Perhaps the most important distinction between design and emergence is that design is an artifact, a product of human cognition, while emergence is an a-cognitive, natural process of self-organization not determined by an intelligent, autonomous agent. Nevertheless, we believe that emergence can be anticipated, harnessed, or cultivated by a human designer. Capra (2002) characterizes this distinction as follows:

We sometimes speak of the structural "design" of a blade of grass or an insect's wing, but in so doing we use metaphorical language. These structures were not designed; rather they were formed during the evolution of life and survived through natural selection. They are emergent structures. Design requires the ability to form mental images, and since this ability, as far as we know, is limited to humans and other great apes, there is no design in nature at large. (p. 120)

Although Capra is literally correct to say nature does not design, we find the metaphor useful because we believe human designers can improve their craft if they study the way biotic organisms emerge. Natural selection is not a designer, as Capra implies, nevertheless we believe the process of natural selection and its role in biotic emergence is important to understand because it has lessons for human designers.

Another difference is that designers are constrained by the whims of the marketplace and their culture whereas in emergence any system that can self-organize, emerge, and survive is viable. The emergent system does not have to please anyone or any thing outside itself. It just needs to find a niche where it can do its thing. The designer, on the other hand, has to please the potential patrons in the marketplace. In some sense a truly innovative design will also create or find a niche for itself in the marketplace. For example the cell phone created a new marketplace for mobile telephony, which initially included business people, then teenagers, and then those who suddenly needed a second phone that was mobile. Once this new marketplace - this new ecological niche - was created, other life forms moved in such as ring tones, games, the Internet, iTunes, and TV mobisodes. The secret is that the designer must seek to tap into some form of latent behavior in the marketplace of potential users. This is made possible through the careful reading of the signals of present-day trends, through which users reveal their latent desires for innovation.

\section{HYPOTHESIS: "AN INNOVATIVE DESIGN IS AN EMERGENT DESIGN"}

There is still one very important difference between emergence and design that we did not cover in the last section and that has to do with innovation. All forms of emergence entail innovation because, by definition, emergence results in new behaviors or properties not associated with the lower level components of the emergent phenomenon. The new behavior also represents an improvement or else it would not have been selected. It should be noted, however, that not all design results in innovation, i.e. an improvement in the product or service. In fact much design results in a product that is different but not really improved. The motivation for this kind of design is to come out with a new model each year or a new line each season so that consumers will continue to purchase the latest fashion. As Shakespeare pointed out, fashion wears out more clothes than those that wear them. Design that does result in innovation is an emergent phenomenon, in that some new functionality or property of the tool or service, not associated with the components that went into the new design, has emerged.

For an innovation to emerge as successful (an "innovation by design"), the intentional activities behind it must seek to understand and incorporate both design and emergence, with each playing its different and respective role. But how does one incorporate both design, an intentional activity, and emergence, a selforganizing principle, in the same process? The solution to this problem will reveal the secret of innovative design. We do not claim to have uncovered this secret but we wish to probe some possibilities that might shed light on this interesting problem. At the minimum we hope that we have at least formulated a problem worthy of consideration and one that will stimulate a dialogue. 
- Characterized by the intentionality of the human designer

- Cognitive and conceptual

- Top-down

- Controlling

- Fixing relationships

- Setting constraints
- Characterized by the autonomy of massively multiple agents or components

- A-Cognitive and conceptual

- Bottom-up

- Influencing

- Maintaining relationships

- Exploring/testing constraints

Table II. Differences of Design and Emergence

One characteristic of emergence is the involvement of multiple, autonomous agents, which in the case of innovative design translates into a community of users. The innovative designer should therefore "design into" an existing community or seek to build a community around a new idea. This will require a new kind of circumspect and anticipatory attitude and, as is the case with natural emergence, a trial-and-error approach through a bevy of testing activities. The notion that successful innovation requires a "fail early, fail often" attitude is in fact exactly the way in which nature operates. Nature is constantly probing the Adjacent Possible (Kauffman, 2000) and sloughing off her failures until she hits upon a success with an improved fitness. The innovative designer must continually probe the Adjacent Possible of his/her product or service until he/ she hits upon a version that has improved market fitness.

\section{HYPOTHESIS: “A HOMEOSTATIC RELATIONSHIP BETWEEN DESIGN AND EMERGENCE IS A REOUIRED CONDITION FOR INNOVATION"}

The lesson or takeaway for entrepreneurs, inventors, designers, and managers is that a better understanding, deployment, and harnessing of both design and emergence is essential to the successful invention, introduction, and marketing of new products, services, and systems. Within the development and management of complex, human-oriented systems, design and emergence should function in dynamic balance. In the discourse of complex systems this kind of dynamic balance is known as a homeostasis.

One of the challenges that must be overcome is that design is largely a top-down activity interested in the control of variables, while emergence is largely a bottom-up activity that rises through the independent but patternforming activity of autonomous entities or agents that are self-organizing. This is why it is absolutely essential that the designer allow the marketplace of potential users to play a significant role in their work.

\section{EXAMPLES OF HOW DESIGN AND EMERGENCE HAVE WORKED TOGETHER AND LED TO INNOVATION}

A critical review of innovation from prehistory to the present reveals a striking pattern of interplay between design and emergence. The very first technologies that humankind made use of were stone flake tools that were actually inherited from their pre-human hominid ancestors, beginning with Homo habilis (handy man) and later somewhat refined by Homo erectus (erect man). These tools were not designed but, rather, they emerged through trial and error. Each tool was designed and manufactured by its user and those who could create a decent tool had a fitness advantage over those who could not. In this very primitive stage of human innovation design and emergence were one.

The next tool that humans developed was not a physical tool but instead was a conceptual and communication tool, namely speech or language. Human language occupies a special place in the biosphere. It is a product of human conceptual thought (Logan, 2006a, 2006b) and represents an emergent phenomenon in which its organization is propagated from parents to their children. After the emergence of language there was an explosion of new tools that were created about 100,000 to 150,000 years ago (Bickerton, 1995, p. 65). The explosion of technological innovation in tool making coincident with the emergence of language and the first appearance of modern man provides evidence of the rapid increase in cognitive abilities that speech made possible.

With language, humans were capable of symbolic thought and another tool that developed alongside language, namely, culture. Geertz $(1973$, p. 8) defines culture as "an historically transmitted pattern of meanings embodied in symbols, a system of inherited conceptions expressed in symbolic forms by means of which men communicate, perpetuate and develop their knowledge about and attitudes towards life". He goes on to add that "culture is patterns for behavior not patterns of behavior". Dawkins (1989) and others have characterized the propagation of language and culture as the replication of memes. Christiansen $(1994,1995)$ and Deacon (1997) have likened language to an organism 
that Christiansen and Ellefson (2002) have described as "a kind of beneficial parasite - a nonobligate symbiant - that confers some selective advantage onto its human hosts without whom it cannot survive". Logan (2006b) has extended Christiansen's notion of regarding language as an organism to regard culture as an organism also.

\section{So language and culture represent examples of} phenomena that were both designed and emergent at the same time, and there is no doubt that they represent critical innovations that ensured human survival and distinguish humans from all other non-human animals. Language allowed human to conceptualize and discuss things that were not immediately perceptible, which made planning possible. Culture, on the other hand, is highly adaptive in that it encodes all of the lessons of survival from one's ancestors. Culture allows one to avoid the costs that learning entails and enables one to engage in new learning, building from the solid foundation of past knowledge. This is a key prerequisite for innovative design, namely improving on past successful designs rather than starting from scratch. Janzoons Coster designed his press on the Chinese model and improved it, and then Gutenberg picked up from where Janzoons Coster left off and went on to create one of the most monumental innovations of all time.

\section{SINCE DESIGN IS A CULTURAL ACTIVITY AND CULTURE IS AN EMERGENT PHENOMENON, IT FOLLOWS THAT DESIGN LEADING TO INNOVATION IS ALSO AN EMERGENT PHENOMENON}

Other examples of emergent phenomena that entail human design include writing, mathematics, science, computing, and the Internet, each of which represents a form of language with its own unique semantics and syntax. Each form of language is also a tool that permits communication and the processing of information. Lang uage $=$ communications + informatics. It has been shown (Logan 2004b) that these five forms of language together with speech form an evolutionary chain of six languages with each new language emerging from the previous forms of language as a bifurcation to a new level of order à la Prigogine (1997) in response to an information overload that the previous set of languages could not handle.

Writing and mathematical notation arose in Sumer c. $3000 \mathrm{BCE}$, as a response to the need to keep track of the tributes farmers paid to priests in the form of agricultural commodities, as documented by SchmandtBesserat $(1978,1992)$. This gave rise to formal schools to teach the skills of reading, writing, and arithmetic (the 3 Rs), which in turn led to scholars and scholarship, giving rise to an overload that science (organized knowledge) was able to deal with. The language of science and its methodology emerged from writing and mathematics in ancient Greece some 2500 years ago. The methods and findings of science are expressed in the languages of writing and mathematics but science may be regarded as a separate form of language because it has a unique way of systematically processing, storing, retrieving, and organizing information, which is quite different from either literature or mathematics

A little more than 60 years ago, responding to the information overload created by science and sciencebased technology, the next system for processing information emerged from science and mathematics in the form of computing, with its own unique cybernetically based and automated methods for processing and organizing information. Computing gave rise to its own information overload. This in turn led to the latest form of language that emerged from computing and telecommunications in the form of the Internet, the World Wide Web, and all of the digital "new media" associated with the Net.

Each of the six forms of language arose as emergent phenomena through innovative design and cultural evolution. Each was developed, bottom-up, by a community of users through trial and error. The six languages of speech, writing, mathematics, science, computing, and the Internet form a nested set of languages in which the later forms contain all of the elements of the earlier forms. This is an important lesson for emergent design. A true innovation incorporates all of the successful features and elements of the designs upon which the new design is built.

Design is a cultural activity in which all of the lessons of the past are exploited. Boyd and Richerson (1985, p. 14) offer observations on the advantages of culture to human survival that apply to the design process as well: "Individual learning ... can be costly and prone to errors. Learning trials occupy time and energy .... Cultural inheritance is adaptive because it is ... a shortcut." Their description of culture (ibid., p. 34) applies with equal force to design: "The essential feature of culture is social learning, the nongenetic transfer of patterns of skill, thought, and feeling from individual to individual in a population or society." Given that the design process operates within the context of culture, and that culture is an emergent phenomenon, innovative design is therefore an emergent phenomenon as well. Technology and tools evolve like organisms; however, their exploration of the Adjacent Possible is not random, as is the case with living organisms, but directed by the creative decisions of the designer.

Another analogy between culture and design is the fact that both are extra-somatic, that is to say, they propagate outside the body of the organism. Culture provides an extra-somatic form of instruction that provides individual human organisms with an 
added margin of survival benefit. The information is extragenetic yet it plays a role not unlike genetically transmitted instincts. Just as instinctual behavior is subject to change and evolution so too is culturally constrained behavior. Just as instinct supports survival so does culture. The same arguments can be applied to design, which must respond to a changing social and technological environment. And just as culture supports survival, design supports survival in the marketplace.

Tomasello $(1999$, p. 4) points out that although there are isolated cases of non-human culture among primates and songbirds, for example, no other species builds on the accomplishments of its earlier cultural achievement to create, as is the case with humans, a constantly evolving and progressing culture. Tomasello et al. (1993) have dubbed this capability "the ratchet effect". Logan (1995, pp. 125132; 2004b, pp. 123129) has independently identified a similar mechanism, "the cognitive, social and technological interplay of language" in his studies of the evolution of notated language, which also describe the process of innovative design:

Cognitive tools and physical technology are two resources at the disposal of human innovators, and the needs or demands of society are often the motivating force. Necessity is the mother of invention, yet invention does not occur in a vacuum. All of the previous innovations in a culture provide the resources, both cognitive and physical, for the next level of innovation. The previous innovations also contribute to changes within the socioeconomic system that give rise to new social demands. Each new invention, technological innovation, or discovery gives rise to new technical capabilities, new cognitive abilities, and new social conditions. These then interact with the existing economic, political, social, cultural, technical, and cognitive realities of the culture to set the stage for the next round of innovation. Thus, technological change in our model is part of an ongoing iterative process. It began with the inception of Homo sapiens and continues to this day at an everquickening pace.

Ideal design, or what we might call "design for emergence", works by removing the barriers to see the new emerging patterns in society. The core concepts and dynamics of emergence have only recently become clear through the analytical and modeling capability of high-speed computing. Not surprisingly then, some of the best places to witness design harnessing emergence are those fields where design employs computer simulation and networked data structures to actively influence the creation and evolution of complex systems.

Familiar examples of designing for emergence from the realm of software include the techniques of collaborative filtering, best known through the recommendation system of Amazon.com, as well as the free, opensource encyclopedia, Wikipedia. All opensource software projects in fact leverage the dynamics of emergence and design. Beta-testing software to find bugs is a further timetested technique.

Turning to social software and recent developments collectively labeled as Web 2.0, we find another phenomenon that reveals characteristic patterns of designing for emergence. "Folksonomy" is a neologism combining "folk" and "taxonomy". The term refers to the rising popularity of online systems allowing users to upload and tag their own links, photos, and other content with keywords of their own choosing, as an aid to sorting and relocating desired material. Unlike formal, topdown classification methods that rely on authoritative, controlled vocabularies, the keyword "clouds" of folksonomies arise in a bottom-up fashion within the non-hierarchical communities of freely available, public websites such as Flickr.com and Del.icio.us.

In the realm of language we find examples that represent a powerful synergy between design and emergence. The story of the Oxford English Dictionary (OED) is such a story. The OED, which today holds over 300,000 entries comprising over 350 million printed characters, did not begin in the form of a prescribed, top-down record assembled by some sort of language police but as an open-source project to record the full extent of natural English usage. The OED's policy was and is to attempt to record all known uses and variants of a word in all varieties of English, worldwide, past and present. In the mid-nineteenth century, assembly of the dictionary proceeded in bottom-up fashion when its founders empowered a huge number of volunteers to read books, copy illustrative passages of words as they were actually used onto quotation slips, and mail them to the editor (Winchester, 2003).

Examples outside software and computing are more difficult to identify. This is perhaps because the massive speed and complexity of contemporary computers makes them one of the few tools that can accelerate evolutionary dynamics and aggregate the volume of information necessary to simulate, model, or actually produce emergent effects. Through the assistance of computer modeling, however, numerous architectural and structural engineering uses of genetic algorithms are currently being championed and built. One articulate proponent of such architectural techniques is the Design and Emergence Group in the United Kingdom (Hensel et al., 2004).

Perhaps the simplest and most poetic instance of designing for emergence in the physical realm is the practice of allowing users to determine the design of paths in the landscape of a campus or building complex. Martin Oetting, author of the blog 
consumerempowerment. com (2006), recounts a story told by his father who visited a Swedish housing project:

The buildings were already finished, but my father was surprised to notice that apparently the company had not planned to build any proper paths or routes, so the tenants could walk between the houses, to the street, to parking spots, etc. Instead, they had only sown out grass seeds. He asked one of the people from the company: "Well, aren't you going to build any pathways between the houses?" The man answered: "Of course we will, but shouldn't we first wait and see where people will be walking?" The company simply wanted to wait a year and see where people would tread down the grass, so they could fit the pathways to the tenants' habits.

One advantage of designing for emergence is that it seems to offer benefits similar to those of natural selection, by developing forms that are resilient and adaptable. We may wonder, then, whether such systems are open to intentional abuse. The answer is yes, for one such example is the phenomenon known as "astroturfing". This term has arisen within the circles of American politics and marketing to describe the artificial, top-down generation of what purports to be the effects of bottom-up, grassroots organization. The intention is to create the illusion of independent public reaction to a political candidate, product, service, or other offering, yet the effect in question reveals itself, on closer inspection, to be deliberately engineered as part of a public relations effort. While this kind of "communications arms race" gives cause for concern, it should nevertheless be noted that designing for emergence has the capacity to exploit the network dynamics of multi-agent systems in a manner that tends to increase overall robustness.

\section{THE RELATIONSHIP BETWEEN HUMAN AND NATURALLY “DESIGNED" SYSTEMS}

All living organisms or biotic agents arise through a process of what we might call natural design. Natural design is not "intelligent design" - it is, in essence, "unintelligent design", as the final design that emerges is the sum of random mutations that have been selected because of their superior fitness. The analogy with human design is that if one considers the set of designs for a generic product or service then this set of designs, each varying slightly from the other, represents a range of mutations from which the marketplace selects on the basis of superior fitness for the needs of purchasers. This mechanism works wherever a free marketplace and competition exist. One of the reasons behind the widespread failure of the Soviet Union to produce consumer goods of value was the lack of a free marketplace. The People's Republic of China, though a communist state, has not suffered the same fate as the Soviet Union because it has allowed a marketplace to operate. The market plays the role of natural selection in the evolution of goods and services.

In nature, when a product no longer appeals to the "market" or ecosystem, the system has a way to recover "market share." Thus dinosaurs, which in large part became extinct, are known to us now primarily through the fossil record. Yet, significantly, a small number survived and evolved to become birds. In this sense it might be said that "birds=dinosaurs 2.0".

One of the sources of innovation in naturally designed systems is something called an exaptation, in which a component of an organism that was adapted for one purpose suddenly becomes the source of a new function. Examples include insect wings, which were originally cooling devices that became exapted for flight. The same is true of dinosaur wings, which were originally upper limbs that were used to scoop up prey more efficiently and also exapted into devices for flight. Another example was a bladder that fish used to regulate the depth to which they could descend by changing the mixture of air and water the bladder held. Through exaptation this device evolved into lungs and led to the emergence of land animals.

We believe that exaptation plays an important role in human design. Examples include the airplane, which was exapted from the bicycle by two bicycle mechanics, Wilbur and Orville Wright. The Newcomb steam engine was designed to pump water out of coal mines but was exapted by James Watt to harness steam for locomotion and the operation of factories that were originally powered by water wheels and windmills. The Gutenberg movable type press was another example of an exaptation of the wooden block print system of text, which itself was an exaptation of textile printing. Exaptation is perhaps the ultimate form of design creativity.

\section{DISCUSSION AND CONCLUSIONS}

We have distinguished between two aspects of technology as a means of propagating organization. First there is the material part of the technology and second there are the concepts and organization that go into the creation of the physical tools that propagate. The concepts and organization of the technology are the "design", in the sense of plan or blueprint, for, as we pointed out earlier, "design is creation for reproduction". The design of a technology is what propagates from one material instantiation to another. It is also the design that undergoes evolution or "descent with modification". We have seen that innovation is the development and diffusion, that is to say the emergence of a new design of a technology that improves its functionality, ease of use, or emotional appeal. 
We noted that emergence refers to a new set of properties that arise from a new arrangement of the components of an entity that did not pertain to the individual components. The design of an entity, then, is the assemblage of a set of components that is able to achieve a function or purpose that the components by themselves cannot achieve.

A key element of a design is its purpose. A living organism is an autonomous agent acting on its own behalf in order to replicate itself and to propagate its organization. A design also has a purpose and it is intended to propagate itself. We may therefore, in a metaphorical sense, think of a design as an organism. Just as an organism comes into existence through a process of emergence or self-organization, so it may be with a design. The designer may operate as the catalyst that allows a design to self-organize. The master designer should consider the possibility of allowing the purpose of the tool to take over and allow it to design itself.

In school and in industry, designers currently receive too much top-down training characteristic of the first industrial revolution and its accompanying emphasis on mechanical mass production. High modernist design in particular is rife with the discourse of control. Today design represents a role and set of responsibilities afforded - and necessitated - by the efficiencies of the machine. Historically, this notion of design was born out of a separation of roles, a pattern common to all branches of the discipline. Increasing quantities of production meant greater responsibility, replete with increasing class distinctions between white-collar designers and blue-collar manufacturers. Designers became givers of form whose function was to determine and control very specific attributes of the product.

Maldonado's definition of industrial design, adopted by the International Council of Societies of Industrial Design (ICSID), provides a case in point: "Design is a creative activity that consists in determining the formal properties of objects that are produced industrially" (quoted in Deforge, 1990). Even Papanek (1971), whose Design for the Real World revealed deep concern for emergent ecological and social forces, offered this very "top-down" definition: "Design is the conscious and intuitive effort to impose meaningful order."

With the rise of industrialization and the Taylorist division of labor, the design function lost its original basis in artisanship. Instead design became increasingly the responsibility of professional engineers and newly minted design specialists. Something was lost, however: that slow process of trial and error based in real-time performance within a real community of users, which was replaced by, at best, prototyping and testing. More often than not, prototyping has been but a pale shadow of the lengthy process that has given us our most reliable forms. The design process, thus speeded up so as to reduce the time to develop new products and services, has unwittingly participated in a massive loss of quality in the dash to the marketplace.

Against this admittedly romantic and backward- looking lament we may posit a fearless call for new progress. For, in a moment of great irony, design is beginning to harness the massive speed and power of digital modeling to retrieve many of the benefits of the unthinkably slow processes of the pre-industrial era. Robust designs of the kind that once emerged through painful trial and error, that achieved optimum functionality before propagating through imitation, may once again emerge from the luminescent screens of our fastest machines.

\section{EMERGENCE AS NATURE'S FORM OF DESIGN}

The question of control versus influence is the crux of the contrast between design and emergence. Nature does not control; she merely accepts whatever is the best fit. Natural selection, the force that selects, is the result of the aggregate of environmental factors and the attrition of individuals incapable of mating.

Perhaps human designers can learn from nature new ways to design more effectively. What is her secret? Well to start with she spawned these creatures, life forms that could organize themselves, act in their own selfinterest, adapt to changing conditions while continually and relentlessly searching for improvements, thereby creating new species, new genres and even new taxa. Nature did not actively spawn these creatures - she merely created a set of physical laws, including organic chemistry, which allowed them to emerge though self-organization. And why were these creatures able to achieve this magnificent accomplishment? The answer is so simple it is often overlooked. They had purpose - the purpose to propagate their organization. Those that were able to realize that purpose survived, lived, and bred, and those that were not able fell by the wayside and were heard from no more.

So what is the bottom line for the designer? Purpose must be the starting point, the motivating factor. Next the materials must be in place, the elements that will go into the design. Then the designer must catalyze the process so that elements of the design self-organize into a pattern that can achieve the purpose or telos of the design.

These four elements represent the four causes of Aristotle: material, formal (the pattern), efficient (the designer), and final or telos cause (the purpose). The designer is the efficient cause trying to make the final cause - the purpose. Designing is causing. 


\section{ACKNOWLEDGEMENTS}

The authors wish to acknowledge the generous support of the Beal Institute for Strategic Creativity, especially the director Alexander Manu, and the research team, in fostering and facilitating the development of this work.

\section{REFERENCES}

Anderson, P. W. (1972). More is different. Science, 177, 393-396.

Bickerton, D. (1995). Language and human behavior. Seattle: University ofWashington Press. (1996 edn. London: University College London Press)

Boyd, R., \& Richerson, P. H. (1985). Culture and the evolutionary process. Chicago, IL: University of Chicago Press.

Capra, F. (2002). The hidden connections: A science for sustainable living. New York: Anchor Books.

Christiansen, M. (1994). Infinite languages finite minds: Connectionism, learning and linguistic structure. Unpublished doctoral dissertation, Centre for Cognitive Studies, University of Edinburgh UK.

Christiansen, M. (1995). Language as an organism implications for the evolution and acquisition of language. Unpublished manuscript, Washington University.

Christiansen, M., \& Ellefson, M. (2002). Linguistic adaptation without linguistic constraints: The role of sequential learning in language evolution. In A. Wray (Ed.), The transition to language (pp. 335-358). Oxford: Oxford University Press.

Dawkins, R. (1989). The selfish gene. Oxford: Oxford University Press. (Original work published 1976).

Deacon, T. W. (1997). The symbolic species: The co-evolution of the brain and language. New York: W. W. Norton.

Deforge, Y. (1990). L'oeuvre et le produit. Champ Vallon: Milleux.

Geertz, C. (1973). The interpretation of culture. New York: Basic Books.

Hensel, M, Menges, A., \& Weinstock, M. (Eds.) (2004). Emergence: Morphogenetic design strategies.

Chichester: Wiley-Academy. Kauffman, S. (2000). Investigations. Oxford: Oxford University Press.

Kauffman, S., Logan, R. K., Este, R., Goebel, R., Hobill, D. \& Shmulevich, I. (In press). Propagating organization: An enquiry. Biology and Philosophy (forthcoming).

Logan, R. K. (1995). The fifth Language: Learning a living in the computer age. Toronto: Stoddart Publishing.

Logan, R. K. (2004a). The alphabet effect. Cresskill NJ: Hampton (1st ed. 1986. New York: Wm. Morrow).

Logan, R. K. (2004b). The sixth language: Learning a living in the Internet age. Caldwell, NJ: Blackburn Press (1st ed. 2000. Toronto: Stoddart Publishing).

Logan, R. K. (2006a). The extended mind model of the origin of language and culture. In N. Gontier, J. P. Van Bendegem, \& D. Aerts (Eds.), Evolutionary epistemology, language and culture. Dordrecht: Springer.

Logan, R. K. (2006b). The extended mind: The origin of language and culture (in press).
Manu, A. (1995). ToolToys: Tools with an element of [lay. Copenhagen: Danish Design Centre.

Oetting, M. (2006). Customer empowerment, Swedish style. Available at: http://www.consumerempowerment. com/? $\mathrm{p}=67$ (accessed 12 January 2006).

Papanek, V. (1971). Design for the real world: Human ecology and social change. London: Granada, 1974 (reprinted 1982).

Prigogine, I. (1997). The end of certainty. New York: Free Press.

Putnam, G. (1962). Books and their makers during the Middle Ages. New York: Hillary House.

Schmandt-Besserat, D. (1978). The earliest precursor of writing. Scientific American, 238(6), 50-59.

Schmandt-Besserat, D. (1992). Before writing, Vol. 1: From counting to cuneiform. Houston: University of Texas Press.

Tomasello, M. (1999). The cultural origins of human cognition. Cambridge, MA: Harvard University Press.

Tomasello, M., Kruger, A. C., \& Ratner, H. H. (1993). Cultural learning. Behavioral and Brain Sciences, 16, 495-552.

Usher, A. (1954). A history of mechanical invenentions. Cambridge, MA: Harvard University Press. (Original work published 1929)

Van Alstyne, G. (2005). Massive Change discussion board. Available at: http://forums.massivechange. com/viewtopic. php?t=15

Winchester, S. (2003). The meaning of everything: The story of the Oxford Dictionary. Oxford: Oxford University Press.

\section{CORRESPONDENCE}

Greg Van Alstyne,

Ontario College of Art \& Design,

100 McCaul Street,

Toronto, Ontario M5T 1W1,

Canada.

E-mail: gvanalstyne@faculty.ocad.ca

Published online 2006-12-01

ISSN 1749-3463 print/ ISSN 1749-3471

DOI: 10.1080/17493460601110525

(C) 2006 Artifact 